\title{
Osteopenia: A Diagnostic and Therapeutic Challenge
}

\author{
Willem F. Lems • Hennie G. Raterman • \\ Joop P. W. van den Bergh • Hans W. J. Bijlsma • \\ Niek K. Valk • M. Carola Zillikens • Piet Geusens
}

Published online: 22 June 2011

(C) The Author(s) 2011. This article is published with open access at Springerlink.com

\begin{abstract}
We discussed whether we are able to select a subgroup of patients with osteopenia having a high fracture risk, in which anti-osteoporotic drug treatment can be advocated. We concluded that in individuals in whom, based on clinical risk factors, a dual-energy x-ray absorptiometry (DXA) was performed in which osteopenia was diagnosed, anti-osteoporotic treatment should be prescribed in those patients with prevalent vertebral fractures, and in patients chronically using glucocorticoids, in a dosage of $7.5 \mathrm{mg}$ per day or more. Although recent developments with regard to high-resolution imaging techniques (eg, peripheral quantitative
\end{abstract}

W. F. Lems $(\bowtie) \cdot$ H. G. Raterman

Department of Rheumatology, VU University Medical Center, Post Box 7057, 1007 MB Amsterdam, The Netherlands

e-mail: wf.lems@vumc.nl

J. P. W. van den Bergh • P. Geusens

Maastricht University Medical Centre/School for Nutrition,

Toxicology, and Metabolism,

Maastricht, The Netherlands

J. P. W. van den Bergh

Department of Internal Medicine, VieCuri Medical Centre,

Venlo, The Netherlands

H. W. J. Bijlsma

Department of Rheumatology and Clinical Immunology,

University Medical Center Utrecht,

Utrecht, The Netherlands

N. K. Valk

Department of Internal Medicine, Rode Kruis Ziekenhuis, Beverwijk, The Netherlands

\section{C. Zillikens}

Department of Internal Medicine,

Erasmus Medical Center Rotterdam,

Rotterdam, The Netherlands computed tomography) seem to be promising, until now they do not provide substantial more reliable information than DXA in the prediction of fractures. We think that more data are urgently needed, since safe and effective drugs are available, but there is uncertainty to which patients with osteopenia these drugs should be prescribed.

Keywords Osteopenia $\cdot$ Glucocorticoids $\cdot$ Vertebral fractures

\section{Clinical Trial Acronyms}

FIT Fracture Intervention Trial

MORE Multiple Outcomes of Raloxifene Evaluation

SOTI Spinal Osteoporosis Therapeutic Intervention

TROPOS Treatment of Peripheral Osteoporosis

\section{Introduction}

In daily practice, postmenopausal women and elderly men are usually treated for osteoporosis based on a low bone mineral density (BMD), namely a T-score of $\leq-2.5$ at the lumbar spine and/or hips. However, it is important to realize that this arbitrarily chosen cutoff point is based on the 1994 World Health Organization defined subcategories of BMD. The different categories are given in Table 1. These cutoff values were originally defined to assess the prevalence of osteoporosis, and not, as is common practice nowadays, to be used as a treatment threshold [1].

Based on these categories, both osteopenic and osteoporotic patients are treated with dietary and lifestyle management (adequate calcium and vitamin D intake, exercise therapy, and prevention of falls), whereas those with T-scores in the osteoporotic range are also prescribed anti-osteoporotic drugs, 
Table 1 World Health Organization criteria for osteoporosis and osteopenia

\begin{tabular}{ll}
\hline Terminology & T-score definition \\
\hline Normal & $\mathrm{T} \geq-1.0$ \\
Osteopenia & $-2.5<\mathrm{T}<-1.0$ \\
Osteoporosis & $\mathrm{T} \leq-2.5$ \\
Established osteoporosis & $\mathrm{T} \leq-2.5$ in the presence of \\
& one or more fragility fractures \\
\hline
\end{tabular}

usually (generic) bisphosphonates. However, it is important to realize that, paradoxically, more fractures occur in patients with osteopenia than in patients with osteoporosis. For instance, in the NORA (National Osteoporosis Risk Assessment) study, a large, population-based observational study in postmenopausal women in North America, it was found that the incidence of clinical fractures was higher in patients with T-scores in the osteoporotic range than in patients with T-scores in the osteopenic range, but the total number of clinical fractures was higher in osteopenic patients than in osteoporotic patients [1].

The same pattern was found in a recent study in Australia, in which $57 \%$ of fractures occurred in patients with osteopenia, and only $27 \%$ in patients with osteoporosis [2]. The explanation for this phenomenon is simple: the number of patients with osteopenia is much higher than the number of patients with osteoporosis.

Strikingly, several effective anti-osteoporotic drugs are available, but these drugs are usually only prescribed in the high-risk group of osteoporotic patients, but not in the much larger group of individuals with osteopenia. In this manuscript, we will discuss the critical question whether we are able to categorize within the individuals with osteopenia, subgroups of high-risk patients, whom anti-osteoporotic drug treatment should be advocated.

\section{Bone Quality and Osteopenia}

In clinical practice, BMD is assessed by dual-energy $\mathrm{x}$-ray absorptiometry (DXA) as the current gold standard test for diagnosing osteoporosis. The relationship between BMD and fracture risk has clearly been established [3]. DXA uses a two-dimensional representation of a three-dimensional structure and expresses the amount of bone in grams per centimeter squared. Recent clinical investigations indicate that BMD only partly explains bone strength and show limitations of BMD measurements in assessing fracture risk and monitoring the response to therapy $[1,4-7]$.

Bone quality is defined as the properties of bone tissue that, in addition to density, contribute to bone strength [8]. These properties include the macro- and microarchitecture and the material properties of bone as well as the efficiency of microdamage repair. Thus, fracture risk is strongly related to bone quality.

New noninvasive and/or nondestructive imaging techniques have been developed enabling quantitative assessment of macro- and microstructural bone features, and improving our ability to estimate bone strength. At present the quality of bone can be partly assessed in daily practice. Quantitative assessment of bone macrostructure can be provided by DXA and CT, particularly volumetric quantitative computed tomography (QCT), whereas assessment of the trabecular and cortical microstructure may be obtained by high-resolution CT and high-resolution MRI.

In recent studies it has been shown that women undergo loss of trabeculae with an increase in trabecular spacing, whereas men mainly sustain trabecular thinning with aging but no net change in trabecular number or spacing [9-11•]. Because decreases in trabecular number have been shown to have a much greater impact on bone strength compared with decreases in trabecular thickness, these findings may help explain the lower risk of fractures in men [12]. Additionally, women have less periosteal expansion, more porous cortices during aging $[10,12]$.

Kazakia et al. [13] showed that osteopenic individuals with identical BMD at the distal radius may have substantial differences in bone parameters that reflect bone quality and bone strength. Comparison of postmenopausal women with and without a fracture showed no difference in areal BMD of the lumbar spine or hip and only a small difference at the distal radius between both groups, whereas there were substantial and highly significant differences in volumetric BMD, microarchitecture, and bone mechanical properties assessed by high-resolution peripheral QCT (HR-pQCT) [14]. Moreover, it has recently been shown by the MrOS (Osteoporotic Fractures in Men) Research Group that peripheral bone strength measures assessed by peripheral QCT are associated with fracture risk and may improve the ability to identify older men at high risk of fracture [15•].

Thus, based on the recent developments and literature, assessment of macro- and microstructural bone features by high-resolution (peripheral CT) techniques can provide additional information regarding bone quality in finite element analysis-derived bone strength, independently of DXA. However, the application of these new imaging techniques for daily practice, especially with regard to selection of individual patients with high fracture risk and treatment decisions, needs to be further studied.

\section{Glucocorticoids and Osteopenia: A Combination with High Fracture Risk}

Glucocorticoids (GCs) are often used because of their strong anti-inflammatory and immunomodulating effects. 
However, their use is limited because of the large number of side effects. Osteoporosis is regarded as one of the most serious side effects, because the bone loss is irreversible and the clinical manifestations, vertebral and nonvertebral fractures, may be devastating [16]. GCs have a direct negative effect on bone formation, by increasing apoptosis of osteoblasts and osteocytes, which is reflected in low bone formation markers (eg, osteocalcin) [16]. Conversely, bone resorption may be elevated in the initial phase, related to high levels of receptor activator of nuclear factor- $\mathrm{KB}$ ligand; the combination of low bone formation and elevated bone resorption may lead to rapid bone loss and fractures. Later on, bone resorption is depressed in chronic GC users, probably resulting from the coupling between bone formation and bone resorption $[17,18 \bullet \bullet$.

In addition, GCs negatively influence calcium homeostasis by decreasing calcium absorption in the gut and calcium reabsorption in the kidney, and have unfavorable neuroendocrine and neuromuscular effects. In a very large observational study, it has been shown that the risk for clinical fractures is dose related: for example, for hip fractures, there is no elevated risk in prednisone users with a mean daily dosage of less than $2.5 \mathrm{mg}$ per day, whereas in those with dosages between 2.5 to $7.5 \mathrm{mg} /$ day the relative risk (RR) was 1.77 (95\% CI, 1.6-2.0) and in those between $7.5 \mathrm{mg}$ per day the RR was 2.27 (95\% CI, 1.9-2.7). The same pattern was found for vertebral fractures: an RR of 1.6 in patients using less than $2.5 \mathrm{mg}$ of prednisone per day up to an RR of 5.2 in those using more than $7.5 \mathrm{mg}$ per day [16]. These data show that fracture risk is dose related, but it is important to realize that higher dosages are prescribed to patients with higher disease activity, and that the underlying disease activity also has strong effects on bone (metabolism). Therefore, it might be more appropriate to use the term GC-associated osteoporosis, instead of GCinduced osteoporosis. There is an ongoing discussion about whether the fracture threshold for BMD is changed during the use of GC: Van Staa et al. [19] showed that the risk for vertebral fractures was two to three times higher in GC users versus non-GC users (for the same BMD).

For all these reasons, it can be argued to use a lower threshold for initiating anti-osteoporotic drugs in GC users than in postmenopausal women and elderly men. For chronic users, it has been advocated in the past to have a cutoff value of T-score less than -1 SD (according to American College of Rheumatology Glucocorticoid-Induced Osteoporosis Guidelines 2001) or T-score less than -1.5 in the UK Consensus document $[20,21]$. Because fracture risk is higher in starters, and particularly in the elderly, it can be advocated to start treatment of all osteopenic patients 50 years and over with prednisone in a dosage of $7.5 \mathrm{mg}$ per day or more for at least 3 months.

\section{Vertebral Fractures and Osteopenia}

Vertebral fractures are often missed. For instance, Gehlbach [22] showed that only $50 \%$ of vertebral fractures were recognized by radiologists, and anti-osteoporotic treatment was started in only $25 \%$ of these patients. It is generally thought that vertebral fractures are often not diagnosed because they are usually not related to trauma and fall events, and thus more difficult to recognize than nonvertebral fractures. Also, they can be missed in the search for other diseases (malignancy), or by underestimating the clinical relevance of diagnosing a vertebral fracture [23]. However, prevalent vertebral fractures are associated with a four times higher risk for new vertebral fractures, and a two times higher risk for hip fractures [24]. Lindsay et al. [25] showed that in $20 \%$ of the women with an incident vertebral fracture a subsequent vertebral fracture occurred. In addition, the presence of prevalent vertebral fractures is associated with a decreased quality of life [26]. For these reasons, diagnosing vertebral fractures is clinically relevant. Interestingly, it is nowadays possible to detect vertebral deformities with lateral vertebral assessment (LVA), a software technique imaging the heights of the vertebral bodies that can be used in one session with a BMD measurement of the spine and hips. LVA has the additional advantage of a lower radiation dosage.

How to score vertebral fractures? In most clinical trials, the semiquantitative method of Genant is used, in which a height loss of at least $20 \%$ is arbitrarily defined as a vertebral fracture [27]. Because in comparative studies with conventional radiographs (regarded as the gold standard) the sensitivity and specificity of diagnosing vertebral fractures was slightly lower with LVA, particularly in the upper thoracic region, we propose to use a height loss of at least $25 \%$ for defining a vertebral fracture by LVA. The finding of a height loss of $25 \%$ or more can be used as a threshold for making decisions for starting anti-osteoporotic treatment, usually for 5 years.

The added value of diagnosing a vertebral fracture in a patient with a T-score in the osteoporotic range is limited, since the decision for anti-osteoporotic treatment can be based on the presence of clinical risk factors and the low T-score. In contrast, the consequence of the presence or absence of a vertebral deformity in patients with osteopenia might differ from starting treatment or not. In several studies it has been shown that in around $20 \%$ of the patients with osteopenia a vertebral fracture can be diagnosed [28, 29•]. In line with this, we propose that it is necessary that LVA software becomes widely available, and that radiologists and physicians are adequately trained in detecting vertebral fractures. 


\section{Osteopenia: Evidence for Treatment of Certain Patients?}

Up to now there is no consensus on how patients with low BMD should be treated, as the terms osteopenia and osteoporosis were introduced for diagnostic purposes (to classify patients according to BMD) and not for therapeutic thresholds, thus without direct therapeutic consequences. Therefore, osteopenic patients should not be treated without any other indication for anti-osteoporotic medication. Literature regarding medical treatment of patients with osteopenia is sparse, as most clinical trials focus on patients with osteoporosis and/or the presence of hip or vertebral fractures as inclusion criteria. However, some randomized controlled trials also included osteopenic patients, and data of these studies allowed post hoc analyses in these patients.

\section{Three Different Types of Studies Can Be Discriminated}

\section{Studies with Osteopenic Patients}

In a post hoc analysis of the FIT-1 and FIT- 2 studies in patients with osteopenia of the femoral neck (with a T-score between -1.6 and $-2.5 \mathrm{SD}$, with and without prevalent vertebral fractures), alendronate decreased the risk of radiologic vertebral fractures (RR, 0.57 ; 95\% CI, 0.41$0.81)$ and clinical vertebral fractures (RR, $0.41 ; 95 \% \mathrm{CI}$, 0.19-0.76) [30]. In a post hoc analysis of the SOTI and TROPOS studies in patients with vertebral osteopenia (with a prevalent vertebral fracture or a previous nonvertebral fracture) and in patients with osteopenia at the spine and hips (in which vertebral fracture occurred in $48 \%$ to $52 \%$ and previous nonvertebral fracture in $22 \%$ to $29 \%$ ), strontium ranelate decreased the risk for vertebral fractures in patients with vertebral osteopenia (RR, $0.59 ; 95 \% \mathrm{CI}$, $0.43-0.82$ ) and in patients with osteopenia at both sites (RR, 0.48; 95\% CI, 0.24-0.96) [31]. However, most of these patients also had other risk factors (eg, previous vertebral or nonvertebral fractures, chronic stay in rest home, repeat falls, or family history of fractures). In a post hoc analysis from the MORE study in patients with osteopenia of the total hip, raloxifene $(60 \mathrm{mg} / \mathrm{day})$ decreased the risk on radiologic and clinical fractures [32].

Studies in Patients with Prevalent Fractures, Without BMD Inclusion Criterion

In a primary analysis, risedronate diminished the risk of radiologic vertebral deformities in patients with a vertebral fracture at baseline. The mean T-score in the spine at baseline was $-2.6 \mathrm{SD}$ (1.4), also indicating that patients without osteoporosis were included [33]. Hip fracture patients were included in only one study with fractures as a primary end point. In this study, the use of zoledronate was associated with a lowered RR for vertebral and nonvertebral fractures. At baseline, $59 \%$ of the patients had a T-score at the femoral neck above -2.5 [34].

Studies with Inclusion of Both Osteoporotic and Osteopenic Patients

In several phase 3 studies patients were included with a mean T-score above $-2.5 \mathrm{SD}$ : in the North American risedronate study mean $\mathrm{BMD}$ was $-2.4 \mathrm{SD}$ [35]; in an ibandronate study $-1.8 \mathrm{SD}$ (in the total hip) [36]; in a study with parathyroid hormone (1-84) -1.9 and -2.2 SD (in the total hip and femoral neck, respectively) [37]; with strontium ranelate -2.4 [38]; and with denosumab -2.2 and $-1.9 \mathrm{SD}$, at the femoral neck and total hip, respectively [39]. In the teriparatide study both patients with a mild vertebral fracture and patients with two mild vertebral fractures and a T-score of less than $-1.0 \mathrm{SD}$ at the hip or lumbar spine were included [40]. All above-mentioned studies included patients with a prevalent vertebral fracture with the exception of the denosumab trial, in which only $24 \%$ of patients had prevalent vertebral fracture.

Taken together, these data emphasize that antiosteoporotic drug treatment is effective, particularly in those patients with prevalent vertebral fractures or previous (recent) nonvertebral fractures.

\section{Conclusions}

The critical point is that the majority of fractures occur in patients with osteopenia, whereas the effective and generally safe anti-osteoporotic drugs are usually only prescribed in osteoporotic patients. Although lifestyle measures are advocated in osteopenic patients, among which include adequate calcium and vitamin D supplementation, the question arises which subgroups of osteopenic patients can be defined in whom anti-osteoporotic drugs should also be prescribed. Prescription of these drugs to all osteopenic patients will certainly lead to overtreatment with unnecessary side effects and costs. Theoretically, it would be very attractive to get additional information on bone strength and fracture risk above DXA results with high-tech measurement techniques such as HR-pQCT; unfortunately, these data hardly exist, and these machines are (still) very expensive, and thus their availability is limited. We hope that in the coming years more data will support the use of HR-pQCT in daily practice for estimating the bone strength in patients in which the fracture risk should be estimated, and that these machines become less expensive and more widely available. 
So far, in patients using GCs 3 months or more in a dosage of $\geq 7.5 \mathrm{mg} /$ day, particularly in elderly patients and/ or in those with prevalent vertebral fractures, we advocate prescribing anti-osteoporotic drugs, particularly those drugs in which reduction of vertebral fractures versus placebo was documented (in GC users), or the equivalence or even superiority versus active comparators. The other subgroup we defined is the group of patients with clinical risk factors for osteoporosis and/or a recent fracture, in which a DXA was performed, with a T-score in the osteopenic range, while a vertebral deformity was found on radiographs or LVA.

It will be a challenge to diagnose and adequately treat all osteopenic patients with vertebral deformities and/or the use of GCs, but the first step is to protect the osteopenic patients with the highest risk for future fractures. Whether subjects with a recent clinical fracture and other risk factors for fractures and osteopenia (eg, documented low bone quality) will benefit from anti-osteoporosis medication cannot be concluded from current data but may become more clear in future studies. These recommendations are not the end but the beginning: more research is urgently needed to find out which osteopenic patients benefit form anti-osteoporotic drug therapy.

Disclosure Conflicts of interest: W.F. Lems: has received honoraria from MSD, Amgen, Eli Lilly, and Warner Chilcott; H.G. Raterman: none; J.P.W. van den Bergh: none; J.W.J. Bijlsma: none; N.K. Valk: has received payment for development of educational presentations including service on the speakers' bureau, and has received travel/ accommodations expenses covered or reimbursed from Amgen; M.C. Zillikens: has received honoraria for speaker's fees for several pharmaceutical companies; P. Geusens: none.

Open Access This article is distributed under the terms of the Creative Commons Attribution Noncommercial License which permits any noncommercial use, distribution, and reproduction in any medium, provided the original author(s) and source are credited.

\section{References}

Papers of particular interest, published recently, have been highlighted as:

- Of importance

•- Of major importance

1. Siris ES, Chen YT, Abbott TA, Barrett-Connor E, Miller PD, Wehren LE, et al. Bone mineral density thresholds for pharmacological intervention to prevent fractures. Arch Intern Med. 2004;164:1108-12.

2. Pasco JA, Seeman E, Henry MJ, Merriman EN, Nicholson GC, Kotowicz MA. The population burden of fractures originates in women with osteopenia, not osteoporosis. Osteoporos Int. 2006;17:1404-9.
3. Marshall D, Johnell O, Wedel H. Meta-analysis of how well measures of bone mineral density predict occurrence of osteoporotic fractures. BMJ. 1996;312:1254-9.

4. Genant HK, Engelke K, Prevrhal S. Advanced CT bone imaging in osteoporosis. Rheumatology (Oxford). 2008;47 Suppl 4:iv9-iv16.

5. Bouxsein ML. Technology insight: noninvasive assessment of bone strength in osteoporosis. Nat Clin Pract Rheumatol. 2008;4:310-8.

6. Delmas PD, Seeman E. Changes in bone mineral density explain little of the reduction in vertebral or nonvertebral fracture risk with anti-resorptive therapy. Bone. 2004;34:599-604.

7. Watts NB, Geusens P, Barton IP, Felsenberg D. Relationship between changes in BMD and nonvertebral fracture incidence associated with risedronate: reduction in risk of nonvertebral fracture is not related to change in BMD. J Bone Miner Res. 2005;20:2097-104.

8. Bouxsein ML. Bone quality: where do we go from here? Osteoporos Int. 2003;14 Suppl 5:S118-27.

9. Khosla S, Riggs BL, Atkinson EJ, Oberg AL, McDaniel LJ, Holets M, et al. Effects of sex and age on bone microstructure at the ultradistal radius: a population-based noninvasive in vivo assessment. J Bone Miner Res. 2006;21:124-31.

10. Macdonald HM, Nishiyama KK, Kang J, Hanley DA, Boyd SK. Age-related patterns of trabecular and cortical bone loss differ between sexes and skeletal sites: a population-based HR-pQCT study. J Bone Miner Res. 2011;26:50-62.

11. - Nishiyama KK, Macdonald HM, Buie HR, Hanley DA, Boyd SK: Postmenopausal women with osteopenia have higher cortical porosity and thinner cortices at the distal radius and tibia than women with normal aBMD: an in vivo HR-pQCT study. J Bone Miner.Res. 2010, 25:882-890. This is an important paper focusing on differences in bone strength between women with osteopenia versus those with normal BMD.

12. Seeman E. Bone quality: the material and structural basis of bone strength. J Bone Miner Metab. 2008;26:1-8.

13. Kazakia GJ, Burghardt AJ, Link TM, Majumdar S. Variations in morphological and biomechanical indices at the distal radius in subjects with identical BMD. J Biomech. 2011;44:257-66.

14. Stein EM, Liu XS, Nickolas TL, Cohen A, Thomas V, McMahon DJ, et al. Abnormal microarchitecture and reduced stiffness at the radius and tibia in postmenopausal women with fractures. J Bone Miner Res. 2010;25:2296-305.

15. • Sheu Y, Zmuda JM, Boudreau RM, Petit MA, Ensrud KE, Bauer DC, Gordon CL, Orwoll ES, Cauley JA: Bone strength measured by peripheral quantitative computed tomography and the risk of nonvertebral fractures: the osteoporotic fractures in men (MrOS) study. J Bone Miner.Res 2011, 26:63-71. This is an important paper focusing on differences in bone strength between men with and without nonvertebral fractures.

16. Van Staa TP, Leufkens HG, Abenhaim L, Zhang B, Cooper C. Use of oral corticosteroids and risk of fractures. J Bone Miner Res. 2000;15:993-1000.

17. Van Staa TP. The pathogenesis, epidemiology and management of glucocorticoid-induced osteoporosis. Calcif Tissue Int. 2006;79:129-37.

18. •• Teitelbaum SL, Seton MP, Saag KG: Should bisphosphonates be used for long-term treatment of glucocorticoid-induced osteoporosis? Arthritis Rheum 2011, 63:325-328. This is an editorial bringing up that both bone formation and bone resorption seem to be decreased in chronic GC users, which might have clinically relevant consequences for prescribing anti-osteoporotic drugs in these patients.

19. Van Staa TP, Laan RF, Barton IP, Cohen S, Reid DM, Cooper C. Bone density threshold and other predictors of vertebral fracture in patients receiving oral glucocorticoid therapy. Arthritis Rheum. 2003;48:3224-9. 
20. Recommendations for the prevention and treatment of glucocorticoidinduced osteoporosis: 2001 update. American College of Rheumatology Ad Hoc Committee on Glucocorticoid-Induced Osteoporosis. Arthritis Rheum 2001, 44:1496-1503.

21. Eastell R, Reid DM, Compston J, Cooper C, Fogelman I, Francis $\mathrm{RM}$, et al. A UK consensus group on management of glucocorticoidinduced osteoporosis: an update. J Intern Med. 1998;244:271-92.

22. Gehlbach SH, Bigelow C, Heimisdottir M, May S, Walker M, Kirkwood JR. Recognition of vertebral fracture in a clinical setting. Osteoporos Int. 2000;11:577-82.

23. Lems WF. Clinical relevance of vertebral fractures. Ann Rheum Dis. 2007;66:2-4.

24. Black DM, Arden NK, Palermo L, Pearson J, Cummings SR. Prevalent vertebral deformities predict hip fractures and new vertebral deformities but not wrist fractures. Study of osteoporotic fractures research group. J Bone Miner Res. 1999;14:821-8.

25. Lindsay R, Silverman SL, Cooper C, Hanley DA, Barton I, Broy $\mathrm{SB}$, et al. Risk of new vertebral fracture in the year following a fracture. JAMA. 2001;285:320-3.

26. Oleksik A, Lips P, Dawson A, Minshall ME, Shen W, Cooper C, et al. Health-related quality of life in postmenopausal women with low BMD with or without prevalent vertebral fractures. J Bone Miner Res. 2000;15:1384-92.

27. Genant HK, Wu CY, van Kuijk C, Nevitt MC. Vertebral fracture assessment using a semiquantitative technique. J Bone Miner Res. $1993 ; 8: 1137-48$.

28. Jager PL, Jonkman S, Koolhaas W, Stiekema A, Wolffenbuttel $\mathrm{BH}$, Slart RH: Combined vertebral fracture assessment and bone mineral density measurement: a new standard in the diagnosis of osteoporosis in academic populations. Osteoporos. Int. 2010.

29. - Netelenbos JC, Lems WF, Geusens PP, Verhaar HJ, Boermans AJ, Boomsma MM, Mulder PG, Papapoulos SE: Spine radiographs to improve the identification of women at high risk for fractures. Osteoporos Int 2009, 20:1347-1352. This is a paper documenting that vertebral fractures can be found in around 20\% of osteopenic patients, which can be the difference for treating or not (with anti-osteoporotic drugs).

30. Quandt SA, Thompson DE, Schneider DL, Nevitt MC, Black DM. Effect of alendronate on vertebral fracture risk in women with bone mineral density $\mathrm{T}$ scores of- 1.6 to -2.5 at the femoral neck: the Fracture Intervention Trial. Mayo Clin Proc. 2005;80:343-9.
31. Seeman E, Devogelaer JP, Lorenc R, Spector T, Brixen K, Balogh A, et al. Strontium ranelate reduces the risk of vertebral fractures in patients with osteopenia. J Bone Miner Res. 2008;23:433-8.

32. Kanis JA, Johnell O, Black DM, Downs Jr RW, Sarkar S, Fuerst T, et al. Effect of raloxifene on the risk of new vertebral fracture in postmenopausal women with osteopenia or osteoporosis: a reanalysis of the multiple outcomes of raloxifene evaluation trial. Bone. 2003;33:293-300.

33. Reginster J, Minne HW, Sorensen OH, Hooper M, Roux C, Brandi $\mathrm{ML}$, et al. Randomized trial of the effects of risedronate on vertebral fractures in women with established postmenopausal osteoporosis. Vertebral Efficacy with Risedronate Therapy (VERT) study group. Osteoporos Int. 2000;11:83-91.

34. Lyles KW, Colón-Emeric CS, Magaziner JS, Adachi JD, Pieper $\mathrm{CF}$, Mautalen $\mathrm{C}$, et al. Zoledronic acid and clinical fractures and mortality after hip fracture. N Engl J Med. 2007;357:1799-809.

35. Harris ST, Watts NB, Genant HK, McKeever CD, Hangartner T, Keller M, et al. Effects of risedronate treatment on vertebral and nonvertebral fractures in women with postmenopausal osteoporosis. JAMA. 1999;282:1344-52.

36. Chesnut III CH, Skag A, Christiansen C, Recker R, Stakkestad JA, Hoiseth A, et al. Effects of oral ibandronate administered daily or intermittently on fracture risk in postmenopausal osteoporosis. J Bone Miner Res. 2004;19:1241-9.

37. Greenspan SL, Bone HG, Ettinger MP, Hanley DA, Lindsay R, Zanchetta JR, et al. Effect of recombinant human parathyroid hormone (1-84) on vertebral fracture and bone mineral density in postmenopausal women with osteoporosis. Ann Intern Med. 2007;146:326-39.

38. Meunier PJ, Roux C, Seeman E, Ortolani S, Badurski JE, Spector $\mathrm{TD}$, et al. The effects of strontium ranelate on the risk of vertebral fracture in women with postmenopausal osteoporosis. N Engl $\mathrm{J}$ Med. 2004;350:459-68.

39. Cummings SR, Martin JS, McClung MR, Siris ES, Eastell R, Reid IR, et al. Denosumab for prevention of fractures in postmenopausal women with osteoporosis. N Engl J Med. 2009;361:756-65.

40. Neer RM, Arnaud CD, Zanchetta JR, Prince R, Gaich GA, Reginster JY, Hodsman AB, Eriksen EF, Ish-Shalom S, Genant HK, Wang O, Mitlak BH: Effect of Parathyroid Hormone (1-34) on Fractures and Bone Mineral Density in Postmenopausal Women with Osteoporosis. New England Journal of Medicine 2001, 344:1434-1441. 